\title{
Fire behavior modeling based on simulated field plots
}

\author{
A. Beutling ${ }^{1}$, A. C. Batista ${ }^{2} \&$ R. V. Soares ${ }^{2}$ \\ ${ }^{1}$ Forest Science Department, University of M. Grosso do Sul, Brazil \\ ${ }^{2}$ Forest Fire Laboratory, Federal University of Paraná, Brazil
}

\begin{abstract}
The objective of this research was to develop and adjust fire behavior models based on simulated field plots methodology. The experiment was carried out at the Canguiri Experimental Farm, owned by the Federal University of Paraná, located in Pinhais County, Paraná State, Brazil. Twenty two plots, measuring 2.0 x $6.0 \mathrm{~m}$, were assembled using pine tree tops (1.8 to $2.0 \mathrm{~m}$ high) standing in the ground, in order to simulate natural field conditions. Fuel load $\left(2.0 \mathrm{~kg} . \mathrm{m}^{-2}\right.$ of dry needles), layer thickness $(16 \mathrm{~cm})$, and fuel disposal (homogeneously distributed) were pre-determined. During the burns wind speed, air temperature, and relative humidity were monitored. Fire propagation along the plots produced rate of spread varying from 0.003 to $0.061 \mathrm{~m} . \mathrm{s}^{-1}$, flame heights between 0.75 to $5.63 \mathrm{~m}$, and fire intensity from 30.19 to $582.22 \mathrm{kcal} . \mathrm{m}^{-1} . \mathrm{s}^{-1}$. The results allowed the development and adjustment of models to estimate fire front intensity based on flame height and wind speed, and models to estimate the rate of spread based on flame height, wind speed, and relative humidity. Keywords: prescribed burning, fire behavior, fire models.
\end{abstract}

\section{Introduction}

Fire behavior studies and evaluation constitute an important tool to help fire prediction and suppression activities. However, fire is such a complex phenomenon, involving chemical and physical reactions, that makes difficult an efficient behavior prediction. On the other hand, keeping constant the variables involved in the combustion reaction, and varying only one component at time, it is possible to identify the influence and importance of the elements that compose an experimental fire. Such methodology, however, is far away from reality, 
because the results are obtained from laboratory experimental burnings, subject to several restrictions that makes impossible a significant similarity to the real wildfires.

It is known that laboratory experiments have limitations regarding the fire intensity that can be produced, rendering impossible the fire behavior analysis in conditions similar to a real wildfire. On the other hand, field experiments in natural conditions, even with controlled plots size and vegetation type, are subject to several uncontrolled factors, such as fuel load, moisture content, and fuel disposal, besides the weather parameters.

This research was planned to simulate real fires in field experimental plots, in order to evaluate the fire behavior through the knowledge of some variables involved in the combustion process.

\section{Methodology}

\subsection{Study area}

This research was developed in the Canguiri Experimental Farm, owned by the Federal University of Paraná, located in the Pinhais County, State of Paraná, south of Brazil, approximately at $25^{\circ} 23^{\prime} \mathrm{S}$ and $49^{\circ} 07^{\prime} \mathrm{W}$ (Figure 1). The local climate, according Koppen's classification, belongs to the type Cfb, subtropical humid without a dry season, with mean monthly temperature of the coldest month below $18^{\circ} \mathrm{C}$ and mean monthly temperature of the hottest month below $22^{\circ} \mathrm{C}[1]$.

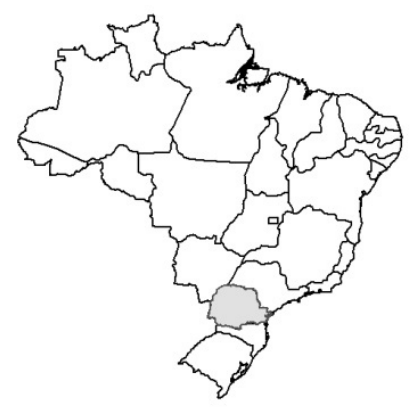

Canguiri Experimental Farm County: Pinhais

State/Country: Paraná/Brazil
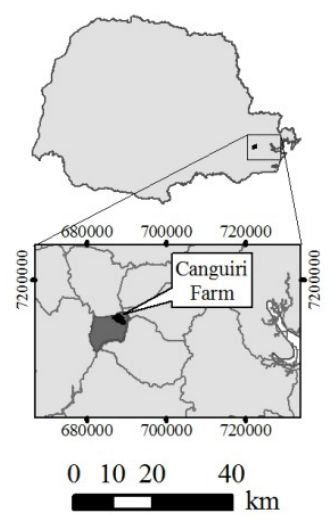

South American 1969 UTM Zone $22 \mathrm{~S}$

Figure 1: Study area location (Credit: Lorena Stolle).

\subsection{Plots installation procedures}

The construction and installation of 30 simulated field plots was done in an area of $100 \times 35 \mathrm{~m}$, presenting a slightly tilted terrain (Figure 2). 


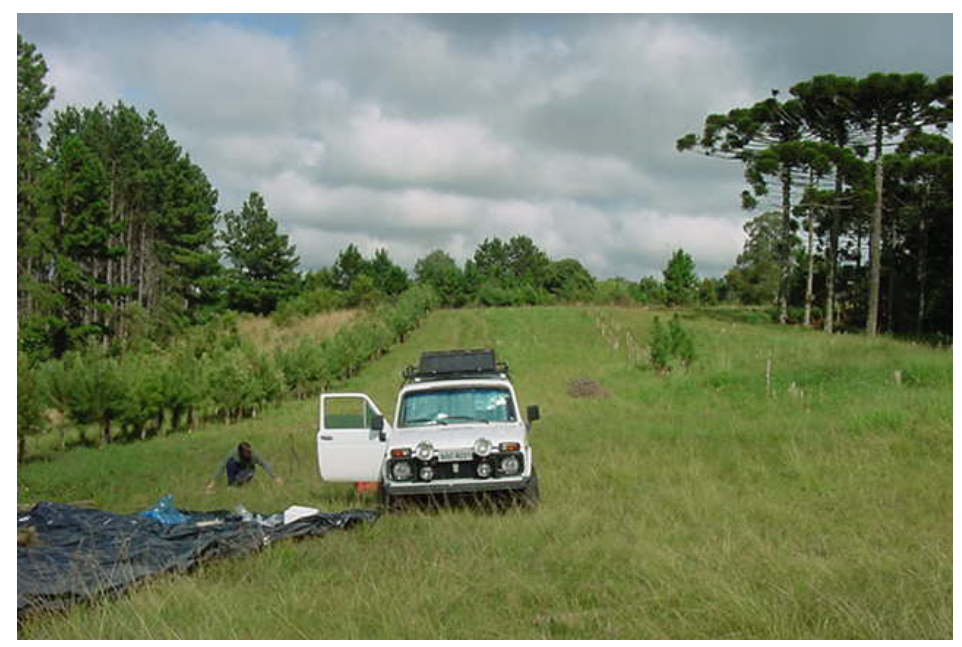

Figure 2: $\quad$ Partial view of the area where the plots were installed.

The field plots assembling and processing were performed in three stages, as follows: material selection, measuring and setting-up the plots, and burning day determination.

a. Material selection:

i. Pinus trees harvesting according to the established dimensions (maximum of $2.0 \mathrm{~m}$ high and no $\mathrm{DBH}$ restriction);

ii. Surface fuel gathering, comprised of fallen Pinus needles collected from plantations existent in the Canguiri Experimental Farm;

iii. Acquisition of Eucalyptus logs to prepare the poles.

b. Measuring and setting-up the plots:

i. Plots size determination ( $2.0 \mathrm{~m}$ wide $\times 6.0 \mathrm{~m}$ long);

ii. Determination of the plots position in relation to the prevailing wind direction;

iii. Positioning of the Eucalyptus poles $(1.0 \times 1.0 \mathrm{~m}$ spacing);

iv. Preparation of the Pinus tree tops (maximum height from 1.80 to $2.0 \mathrm{~m}$, and distance from the crown base to the soil surface $0.80 \mathrm{~m}$ ) (Figure 3);

v. Fixing the Pinus tree tops to the poles, using wire and nails;

c. Burning day:

i. Weighting and distributing the surface fuel throughout the plots (fuel load $2.0 \mathrm{~kg} \mathrm{~m}^{-2}$ and layer thickness 16,0 cm) (Figure 4);

ii. Thermo pairs positioning; 


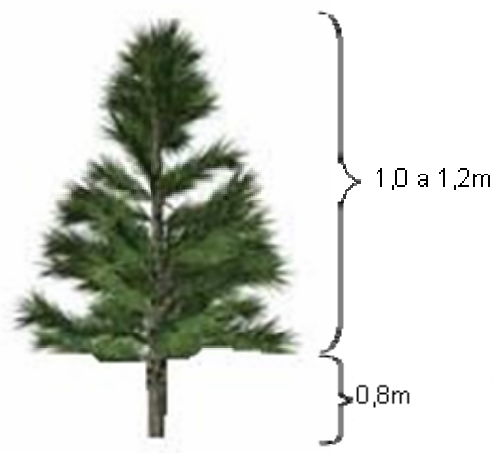

Figure 3: $\quad$ Tree tops dimensions.

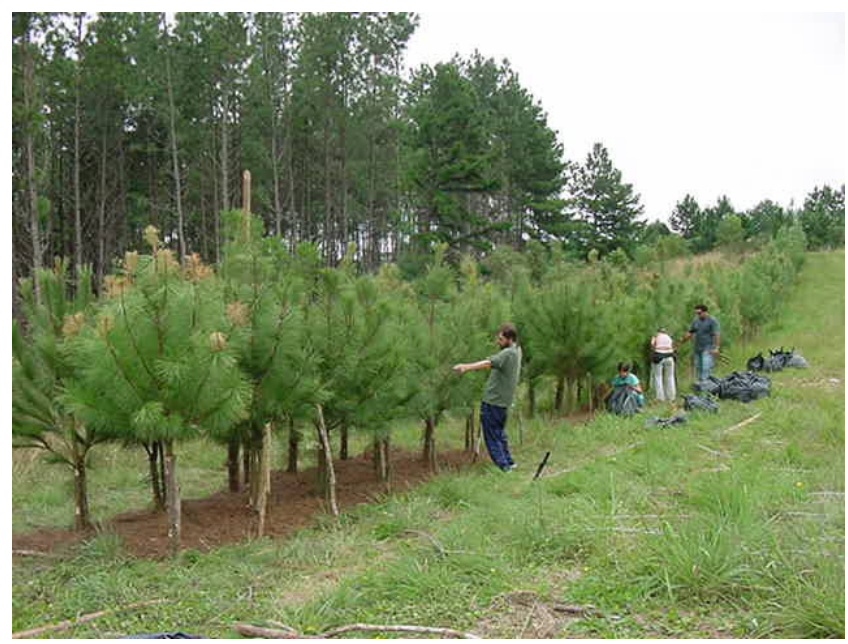

Figure 4: Plots assembling and surface fuel distribution.

\subsection{The proposed methodology}

According to Julio [2], for evaluating the "phenomenon fire" it is necessary to consider the variables and factors of the fire behavior. The fire behavior variables (rate of spread, fireline intensity, flame length, and energy released) express the combustion characteristics, while the fire behavior factors (meteorological conditions and topography) regulate the combustion process and are responsible for the complexity that a wildfire can reach.

This research intend to conduct field experiments for evaluating fire behavior though the control of variables that only would be possible in laboratory studies. For this purpose, variables like fuel type, fuel load, litter layer thickness, physiological stage, and spacing must be previously defined. Plots dimensions, its positioning in relation to the prevailing wind direction, the fuel arrangement, 
and the fire behavior variables to be evaluated also should be anticipated in the planning.

The possibility of making the fire to propagate superficially, slower or faster, or conducting the fire front to climb the crowns, changing the fire type, are some of the possibilities that this methodology could provide.

An important point is that the mentioned variables (plots dimension; fuel load and type; litter layer thickness; trees species, height, diameter, and spacing) could be modified according to the researcher needs or the burning objectives, aiming the attainment of different fire intensity levels and changing related variables, such as rate of spread and flames height, among others. The factors that cannot be controlled during the plots burning are the meteorological variables (wind speed, air temperature and relative humidity) which prevail along the selected burning day. However, these factors can be monitored using a portable weather station. The final result is a series of fire behavior information based on the interactions between known variables and weather conditions [3].

\subsection{Burning and fire monitoring the experimental plots}

In order to evaluate the proposed methodology (fire behavior description and comparison) a series of burnings were conducted in the $2.0 \times 6.0 \mathrm{~m}$ plots, simulating a pine plantation with $1.0 \times 1.0 \mathrm{~m}$ spacing among the trees, and a fuel load of 20.0 Mg.ha- ${ }^{-1}$ (Figure 5).

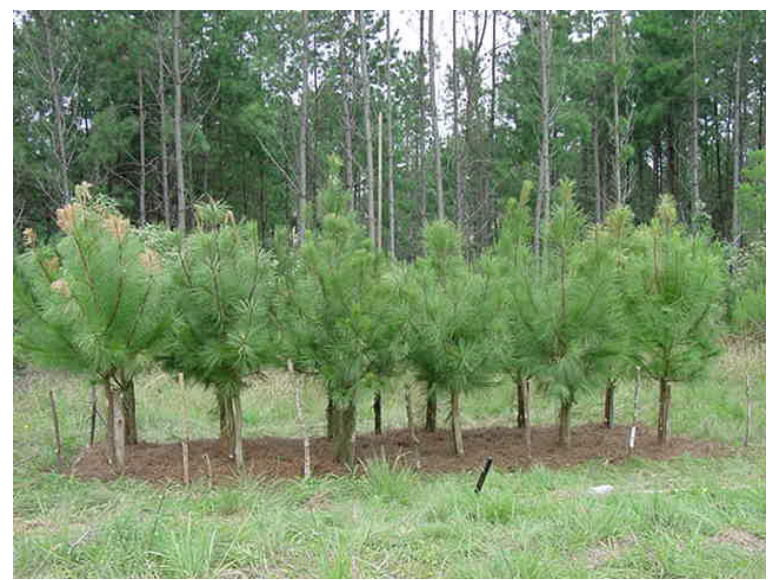

Figure 5: An established plot ready to be burned.

The burnings were carried out from April to August 2007, always between 11:00 AM and 4:00 PM, using the headfire and backfire techniques, observing the prevailing wind directions. Air temperature, relative humidity, and wind speed were monitored and recorded every minute. The fire front progress was timed out and the flames height estimated every $1.0 \mathrm{~m}$ interval. At the end of the burnings the residual fuel was collected and weighted. 


\subsection{Data processing and statistic analysis}

The statistic analysis was performed utilizing the software Statgraphics 4.1. The results were submitted to the analysis of variance and, when significant difference between at least one pair of media, the comparison was made through the SNK (Student-Newman-Keuls) test. The fireline intensity was estimated through Byram's equation [4]. The goodness of fit of the models was tested by the coefficient of determination $\left(\mathrm{R}^{2}\right)$ and the standard deviation $\left(\mathrm{S}_{\mathrm{yx}}\right)$ [5].

\section{Results and discussion}

From a total of 30 experimental burnings carried out in the simulated plots, 22 were monitored and had all fire behavior and associated variables measured and recorded. The burnings were conducted in different climatic conditions, using the headfire and backfire techniques, in order to monitor the fire behavior variables under distinct conditions (Figures 6 and 7 and Table 1).

The moisture content (determined at the Federal University of Paraná Fire Laboratory) of the needles used as surface fuel ranged from 27.55 to $33.24 \%$, and the surface fuel consumption in the burnings varied from 77.31 to $95.80 \%$.

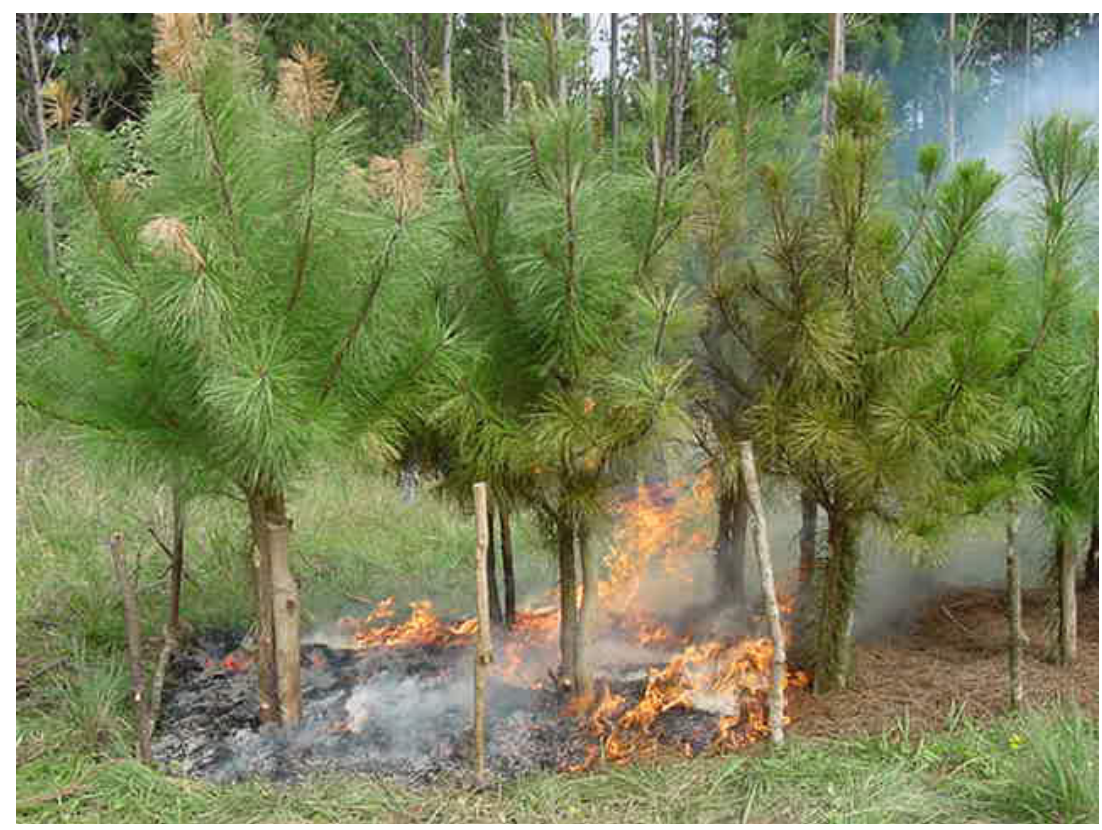

Figure 6: $\quad$ Surface head fire in a recent installed (green trees) plot. 


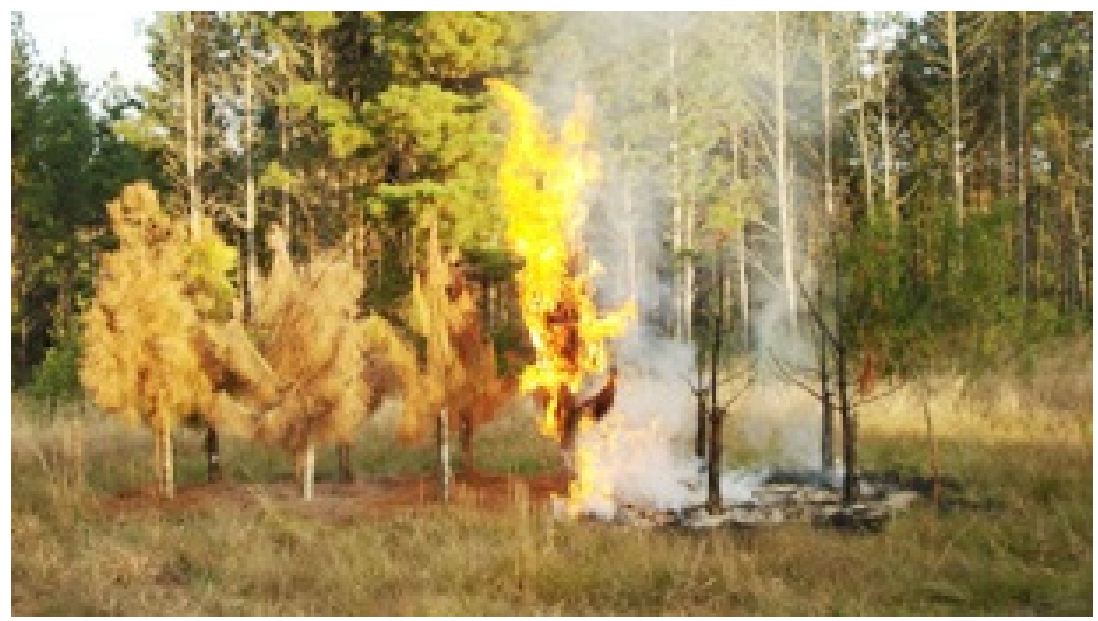

Figure 7: Crown fire in a one month installed (dry trees) plot.

Table 1: $\quad$ Measured variables in the burned field plots.

\begin{tabular}{|c|c|c|c|c|}
\hline Plot & $\begin{array}{l}\text { Burning direction in } \\
\text { relation to the wind }\end{array}$ & $\begin{array}{l}\text { Average rate of } \\
\text { spread }\left(\mathrm{m} . \mathrm{s}^{-1}\right)\end{array}$ & $\begin{array}{c}\text { Medium } \\
\text { flames } \\
\text { height }(\mathrm{m})\end{array}$ & $\begin{array}{c}\text { Fire line } \\
\text { intensity } \\
\left(\mathrm{kcal} \cdot \mathrm{m}^{-1} \cdot \mathrm{s}^{-1}\right)\end{array}$ \\
\hline 1 & Head & 0.015 & 1.00 & 145.3931 \\
\hline 2 & Head & 0.018 & 0.78 & 167.7441 \\
\hline 3 & Head & 0.027 & 0.70 & 259.1773 \\
\hline 4 & Back & 0.009 & 0.88 & 90.0727 \\
\hline 5 & Head & 0.024 & 0.84 & 229.4135 \\
\hline 6 & Back & 0.009 & 0.80 & 89.6254 \\
\hline 7 & Back & 0.009 & 0.98 & 90.3121 \\
\hline 8 & Back & 0.009 & 0.99 & 87.5910 \\
\hline 9 & Back & 0.018 & 1.16 & 168.5835 \\
\hline 10 & Back & 0.006 & 1.23 & 59.1852 \\
\hline 13 & Back & 0.003 & 0.75 & 30.1923 \\
\hline 14 & Back & 0.005 & 1.21 & 54.9842 \\
\hline 15 & Head & 0.041 & 4.75 & 387.6783 \\
\hline 16 & Head & 0.038 & 4.00 & 358.3818 \\
\hline 17 & Head & 0.042 & 3.88 & 397.1266 \\
\hline 18 & Head & 0.035 & 4.13 & 331.0033 \\
\hline 19 & Head & 0.050 & 4.63 & 479.8207 \\
\hline 20 & Head & 0.046 & 4.50 & 434.6930 \\
\hline 21 & Head & 0.040 & 4.75 & 378.8783 \\
\hline 22 & Head & 0.061 & 5.63 & 582.2222 \\
\hline 23 & Head & 0.046 & 5.00 & 438.1933 \\
\hline 24 & Head & 0.056 & 5.50 & 535.5000 \\
\hline
\end{tabular}




\subsection{Description of the fire behavior in the burned plots}

In order to analyze the fire behavior in the burned plots the related variables, grouped according the fire technique (headfire or backfire), were measure and recorded. The minimum, medium and maximum values of the fire variables are presented in Table 2.

Table 2: $\quad$ Summary of the results obtained from the burning field plots.

\begin{tabular}{|c|c|c|c|}
\hline \multicolumn{2}{|c|}{ Backfire burning } & \multicolumn{2}{|c|}{ Headfire burning } \\
\hline \multicolumn{4}{|c|}{ Fire line intensity $\left(\mathrm{kcal} . \mathrm{m}^{-1} \cdot \mathrm{s}^{-1}\right)$} \\
\hline Minimum & 30.1923 & Minimum & 145.3931 \\
\hline Medium & 83.8183 & Medium & 366.0875 \\
\hline Maximum & 168.5835 & Maximum & 582.2222 \\
\hline \multicolumn{4}{|c|}{ Rate of spread $\left(\mathrm{m} . \mathrm{s}^{-1}\right)$} \\
\hline Minimum & 0.003 & Minimum & 0.015 \\
\hline Medium & 0.009 & Medium & 0.038 \\
\hline Maximum & 0.018 & Maximum & 0.061 \\
\hline \multicolumn{4}{|c|}{ Flames height average $(\mathrm{m})$} \\
\hline Minimum & 0.75 & Minimum & 0.70 \\
\hline Medium & 0.97 & Medium & 3.58 \\
\hline Maximum & 1.16 & Maximum & 5.63 \\
\hline
\end{tabular}

According to the numbers showed in Table 2 the headfire burnings produced medium fire intensity approximately 4.4 times higher than the backfire burnings. The average rate of spread was also near 4.2 times higher in the headfires. The fire line intensity ranged from approximately 30.2 to $582.2 \mathrm{kcal} . \mathrm{m}^{-1} . \mathrm{s}^{-1}$ in the backfire and headfire, respectively.

In most wildfires fireline intensity ranges from 400 to $800 \mathrm{kcal} . \mathrm{m}^{-1} \cdot \mathrm{s}^{-1}$, exceeding those values in high intensity fires [6]. Therefore, one of the research objectives, to get values of fire behavior variables close to those observed in wildfires, was reached. The burnings in field artificial plots present a good potential for obtaining fire behavior data similar to those observed in real fires.

The Table 3, adapted from Botelho and Ventura [7], presents a rate of spread classification in four levels. Comparing the table values to those obtained in the burned plots it is observed that the headfires presented a rate of spread classified as "medium", whereas in the backfires the speed was "low".

Table 3: Wildfires rate of spread classification.

\begin{tabular}{|c|c|}
\hline Rate of spread $\left(\mathrm{m} . \mathrm{s}^{-1}\right)$ & Classification \\
\hline$<0.033$ & Low \\
\hline $0.033-0.166$ & Medium \\
\hline $0.166-1.166$ & High \\
\hline$>1.166$ & Very high \\
\hline
\end{tabular}


The headfire burnings produced average flames height about 3.7 higher than those observed in the backfires. In suppression activities, the flame height limit for direct attack is about $1.2 \mathrm{~m}$, what means that the artificial plots burnings provided different situations of fire behavior considering suppression techniques: firstly, in the backfire burnings, it was possible a direct attack as well as the researcher approximation to collect all necessary data; secondly, in the headfire burnings, direct attack and approximation for data collecting were impossible.

\subsection{Modeling fire behavior through mathematical equations}

Many authors have tried to model fire behavior variables using different techniques (Fernandes [8]; McArthur [9]; Rothermel [10]; Rothermel [11]; Rothermel and Deeming [12]; Van Wagner [13]). Perhaps the most used fire modeling system is the Behave, software developed by U.S. Forest Service researchers (Andrews and Bevins [14]; Andrews et al. [15]). However, its use requires several basic data usually unavailable in developing countries.

The data obtained from the artificial plots burning permitted the construction of several mathematical equations to describe the fire behavior. Data processing led to relevant relationships between the variables and factors of the fire behavior, what resulted in the two models (presented below) to estimate fire intensity $(I)$ based on flame height $(h c)$ :

$$
\begin{array}{lll}
I=(8.60203+2.58032 h c)^{2} & \mathrm{R}^{2}=.80 & \mathrm{~S}_{\mathrm{yx}}=0.92 \\
I=117.02+2.69055 h c+13.5249 h c^{2} & \mathrm{R}^{2}=.87 & \mathrm{~S}_{\mathrm{yx}}=22.86
\end{array}
$$

Notwithstanding the lower $\mathrm{R}^{2}$ when compared to the other model, the equation (1) was selected to estimate the fire line intensity based on the flames height average due to the lower standard deviation $\left(\mathrm{S}_{\mathrm{yx}}\right)$, what means higher precision.

The fire intensity was also estimated through the relative humidity $(U R)$ and wind speed $(V v)$, as showed in equations (3) and (4), respectively.

$$
\begin{aligned}
& I=\frac{1}{\left(-0.0139187+\frac{1.49738}{U R}\right)} \quad \mathrm{R}^{2}=.57 \quad \mathrm{~S}_{\mathrm{yx}}=0.01 \\
& I=396.313-635.778 V v+303.636 V v^{2} \quad \mathrm{R}^{2}=.71 \quad \mathrm{~S}_{\mathrm{yx}}=13.24
\end{aligned}
$$

Several models were also developed to estimate the rate of spread based $(r)$ on flames height average $(h c)$, and two of them are showed below:

$$
\begin{array}{lll}
r=(0.683131+0.204798 h c)^{2} & \mathrm{R}^{2}=.80 & \mathrm{~S}_{\mathrm{yx}}=11.63 \\
r=0.335416+0.512357 h c & \mathrm{R}^{2}=.86 & \mathrm{~S}_{\mathrm{yx}}=23.67
\end{array}
$$


For estimating the rate of spread based on the flames height average the equation (5), which presented a better fit considering the $\mathrm{R}^{2}$ and $\mathrm{S}_{\mathrm{yx}}$ values, was selected.

The rate of spread was also estimated through the relative humidity $(U R)$ and wind speed $(V v)$, as showed in equations (7) and (8).

$$
\begin{array}{ccc}
r=\frac{1}{\left(-2.20866+\frac{237.587}{U R}\right)} \quad \mathrm{R}^{2}=.57 & \mathrm{~S}_{\mathrm{yx}}=50.29 \\
r=2.50121-4.01551 V v+1.91813 V v^{2} & \mathrm{R}^{2}=.71 \quad \mathrm{~S}_{\mathrm{yx}}=13.25
\end{array}
$$

The weather variables wind speed and relative humidity also presented some potential to estimate both, the fire line intensity and the rate of spread, with the wind speed always presenting better fits.

\subsection{Final remarks about the methodology}

Some important aspects related to the applied methodology were observed during the experiment conduction that could be resumed as follows:

1) Advantages:

a. A small area is sufficient to carry out the experiment, and several replications could be made just remounting the plots in the same place;

b. The weather variables ( air temperature, relative humidity, and wind speed) could be easily monitored, and the experiment could be run under different conditions;

c. The fuel load and arrangement is controlled and could be changed in order to get different levels of $\mathrm{f}$ ire intensity, including crown fires.

2) Disadvantages:

a. Obtainment of the material (tree tops) that composes the plots;

b. Handiwork and time spent in the plots assembling.

The fire behavior response potential when using this methodology is directly related to an accurate plots assembling and careful experiment conduction.

\section{Conclusions}

During the experiment conduction the flames height ranged from 0.75 to $5.63 \mathrm{~m}$ and the rate of spread from 0.003 to $0.061 \mathrm{~m} . \mathrm{s}^{-1}$ in the backfire and headfire, respectively.

Fire intensity ranged from 30.1923 to $168.5835 \mathrm{kcal} . \mathrm{m}^{-1} \cdot \mathrm{s}^{-1}$ in the backfire burnings and from 145.3931 to $582.22 \mathrm{kcal} . \mathrm{m}^{-1} . \mathrm{s}^{-1}$ in the headfire burnings.

Fire intensity, as well as rate of spread, was better estimated through the average flames height; 
The artificial plots used in this research simulated satisfactorily the fire behavior observed in real wildfires;

\section{References}

[1] IAPAR. Cartas climáticas do Estado do Paraná 1994. Londrina, 1994. 49 p.

[2] Julio, G. Comportamiento del fuego: modelos de simulación y su uso en actividades de combate. In: Reunião Técnica Conjunta FUPEF/SIF/IPEF, 4., 1996, Curitiba; Curso de Atualização em Controle de Incêndios Florestais, 2., 1996, Proceedings... Curitiba: FUPEF, 1996, p. 1117-129.

[3] Beutling, A. Modelagem do comportamento do fogo com base em experimentos laboratoriais e de campo. Curitiba, 2009. Tese (Doutorado em Engenharia Florestal), Setor de Ciências Agrárias, Universidade Federal do Paraná.

[4] Brown, A. A. \& Davis, K. P. Forest fire: control and use. $2^{\text {nd }}$ ed. New York, McGraw-Hill, 1973. 686p.

[5] Steel, R. G. D. \& Torrie, J. H. Principles and procedures of statistics. New York, McGraw-Hill, 1960. 481p.

[6] Soares, R. V. \& Batista, A. C. Incêndios florestais: controle, efeitos e uso do fogo. Curitiba, 2007. 250p.

[7] Botelho, H. \& Ventura, J. Modelos de comportamento do fogo. In: Rego, F. C. \& Botelho, H. A técnica do fogo controlado. Vila Real, Universidade de Trás-Os-Montes e Alto Douro, 1990. p. 49-55.

[8] Fernandes, P. M. Fire spread prediction in shrub fuels in Portugal. Forest Ecology and Management, Amsterdam, v. 144, p. 67-74. 2001.

[9] McArthur, A. G. Fire behavior in Eucalypt forests. Canberra, Forestry and Timber Bureau, 1967. 36p. (Leaflet n. 107).

[10] Rothermel, R. C. A mathematical model for predicting fire spread in wildland fuels. Ogden, USDA Forest Service, 1972. 41p. (Research Paper INT-115).

[11] Rothermel, R. C. How to predict the spread and intensity of forest and range fires. Ogden, USDA Forest Service, 1983. 161p. (General Technical Report INT-143).

[12] Rothermel, R. C. \& Deeming, J. E. Measuring and interpreting fire behavior for correlation with fire effects. Ogden, USDA Forest Service, 1980. 4p. (General Technical Report INT-93).

[13] Van Wagner, C. E. Height of crown scorch in forest fires. Canadian Journal of Forest Research. Ottawa, v.3, p. 373-378. 1973.

[14] Andrews, P. L. \& Bevins, C. Behave fire modeling system: redesign and expansion. Fire Management Notes, Washington, v. 59, n. 2, p. 16-19. 1999.

[15] Andrews, P. L., Bevins, C. \& Seli, R. C. Behaveplus fire modeling system, version 3.0: user's guide. Fort Collins, USDA Forest Service, 2004. 132p. (General Technical ReportRMRS-106). 